\title{
A GESTÃO DE PROJETOS NO SETOR PÚBLICO: OS DESAFIOS DE SUAS ESPECIFICIDADES
}

\author{
THE MANAGEMENT OF PROJECTS IN THE PUBLIC \\ SECTOR: THE CHALLENGES OF ITS SPECIFICITIES
}

Rafael Rudolfo Kreutz ${ }^{1}$ Kelmara Mendes Vieira²

1

Mestrando em Gestão de Organizações Públicas. Universidade Federal de Santa Maria - UFSM 2

Doutora em Administração. Universidade Federal de Santa Maria - UFSM
RESUMO: Na esfera pública, as instituições têm por finalidade desenvolver atividades fins vinculadas às necessidades e interesse da sociedade. Logo, para atender aos anseios populacionais demandam de programas de gestão que possibilitem a utilização racional dos recursos públicos para a promoção de ações que gerem resultados com eficiência. Neste contexto, as metodologias de gerenciamento de projetos surgem como ferramentas de apoio para que as organizações consigam atingir seus objetivos de maneira mais eficaz. Este ensaio teórico tem por objetivo lançar luz sobre as especificidades da gestão de projetos a fim de identificar na literatura quais são os principais fatores de diferenciação da gestão de projetos no setor público. O método de pesquisa utilizada foi uma revisão bibliográfica. Os resultados demonstram serem várias as especificidades do setor público, dessas, algumas levam a uma maior burocracia no processo de gestão dos projetos e que, por consequência, podem acabar gerando uma perda na eficiência do alcance dos resultados pretendidos. Teve destaque a preocupação do setor público quanto à importação de mecanismos de gestão de projetos, que eram originalmente usados no setor privado e a grande diversidade de stakeholders do setor público.

Palavras-chaves: Gestão de Projetos, Setor Público, Especificidade

ABSTRACT: In the public sphere, institutions aim to develop activities that are linked to the needs and interests of society. Therefore, in order to meet the population's needs, they require management programs that allow the rational use of public resources to promote actions that efficiently generate results. In this context, project management methodologies appear as support tools for organizations to achieve their objectives more effectively. This theoretical essay aims to shed light on the specificities of project management in order to identify in the literature the main differentiating factors of project management in the public sector. The research method used was a bibliographical review. The results show that there are several specificities of the public sector, some of them lead to a greater bureaucracy in the project management process and, as a consequence, may end up generating a loss in the efficiency of achieving the desired results. The public sector's concern about the import of project management mechanisms, which were originally used in the private sector and the great diversity of public sector stakeholders, was highlighted.

KEYwORDS: Project Management, Public Sector, Specificities 


\section{INTRODUÇÃO}

A gestão de projetos, cujos benefícios eram poucos reconhecidos até alguns anos atrás, passa a ser considerada gradualmente como um importante instrumento de auxílio para o atingimento dos objetivos organizacionais de maneira eficaz. Estudos mundiais apontam que $69 \%$ das organizações possuem sempre ou na maior parte das vezes, problemas com a realização dos projetos no prazo, 50\% apresentam problemas com custos e $31 \%$ tem apresentado problemas de qualidade em seus projetos. No Brasil isso não é diferente, os números apontam que $67 \%$ tem dificuldades com o prazo, 50\% apresentam problemas com os custos e $32 \%$ com questões referentes a qualidade (PMSURVEY, 2014).

Na administração pública o cenário é bastante similar, as organizações públicas têm apresentado resultados negativos em seus mais variados tipos de projetos. São os conhecidos atrasos das obras e estouro dos prazos planejados, orçamentos que necessitam de suplementação e redefinições constantes do escopo dos projetos, além problemas com a prestação de contas (CARVALHO E PISCOPO, 2014, SEGALA, 2015). Ao mesmo tempo, evidências indicam a falta de maturidade na gestão de projetos em instituições públicas. Por exemplo, Archibald e Prado (2015), a partir de uma pesquisa com 76 profissionais que atuam com projetos em organizações públicas brasileiras identificaram que a maturidade média dessas organizações na gestão de projetos foi de apenas 2,5 em uma escala de 1 à 5 pontos.

Neste contexto, a gestão de projetos, mais comumente utilizada no setor privado, está gradualmente se apresentando como uma alternativa para a busca da elevação no nível de maturidade da gestão de projetos nas instituições públicas e redução do número de projetos públicos que não tem sucesso (CARVALHO E PISCOPO, 2014). Além do mais, auxilia também para atender às pressões da sociedade que fazem críticas públicas e reinvindicações por melhor utilização do recurso público (CRAWFORD; HELM, 2009). Dessa forma, a metodologia de gerenciamento de projetos surge como uma opção facilitadora para as instituições públicas na organização e utilização das melhores práticas gerenciais. Além disso, vem se consolidando como uma iniciativa que possibilita auxiliar os gestores a contribuir para a governança com foco na transparência, accountability, eficiência e efetividade (CLEMENTE et al., 2017).

Entretanto, a implementação de metodologias de gestão de projetos em organizações públicas apresenta especificidades importantes. Em sua essência os projetos públicos acabam sendo políticos (AZMAN et al., 2013), os quais estão sujeitos ao controle social que é exercido em sua maioria das vezes pela mídia e stakeholders, possuem leis governamentais e estão sujeitos a pressão pública (KWAK; ANBARI, 2012). Ademais, por apresentarem um objetivo comum de atendimento aos interesses da sociedade, existe uma necessidade de governança com foco em transparência (CRAWFORD; HELM, 2009). 
Portanto, é necessário o reconhecimento das diferenças e especificidades da aplicação da gestão de projetos no setor público. As dificuldades de adaptação das metodologias do setor privado para o contexto público trazem à tona a necessidade de discussão sobre quais seriam os fatores críticos de sucesso mais significantes para a gestão de projetos (VEZZONi et al., 2013; CARVALHO, PISCOPO, 2014; BESTEIRO et al., 2014; MELO, 2016; silva et al., 2017). No entanto, independentemente da dificuldade de adaptação para o contexto público, observa-se a existência de um processo de consolidação da importância da gestão de projetos dentro das instituições públicas, na mesma medida em que vêm à tona os constantes aumentos de custos, os atrasos em obras de infraestrutura, e o aumento dos casos de corrupção envolvendo o setor público, cresce a pressão para que o aprimoramento da gestão pública e, consequentemente, abre-se espaço para a implantação de novas metodologias como a gestão de projetos.

Neste cenário, percebe-se que existem lacunas de pesquisa significativas quanto à gestão de projetos no campo público (wINCH; SANDERSON, 2015). Dessa forma, pesquisas futuras devem buscar realizar a investigação sobre processos de implementação de boas práticas de gerenciamento de projetos em instituições públicas que obtiveram êxito e que não obtiveram, a fim de buscar compreender como e porque alguns processos foram bem-sucedidos e outros não e assim contribuir para uma melhor compreensão da gestão de projetos no setor público (SINGH, KEIL E KASI, 2009; NASCIMENTO et al., 2011).

Assim, este trabalho busca analisar a gestão de projetos, com foco nas diferenças entre o setor público e o privado. Entende-se que a compreensão destas diferenças seja um passo importante na busca de alternativas e caminhos para a transposição da metodologia de gestão de projetos do setor privado para o setor público.

Dessa forma, o artigo tem sua sequência organizada de maneira que na próxima seção apresenta-se alguns conceitos e características de projetos, em seguida, a importância do gerenciamento de projetos, na sequência, as especificidades do setor público na gestão de projetos e, por fim, as considerações finais.

\section{REFERENCIAL TEÓRICO}

Essa seção busca trazer alguns conceitos, autores e trabalhos acerca do tema gestão de projetos públicos, afim de que o leitor possa compreender de forma mais aprofundada o que está sendo discutido. A mesma está dividida em três blocos, em que o primeiro contempla conceitos e características de projeto, o segundo trata sobre o gerenciamento de projetos e, por fim, o terceiro que aborda algumas das principais diferenças da gestão de projetos entre o setor público e o privado. 


\section{PROJETO, CONCEITOS E CARACTERÍSTICAS}

Na literatura pode-se encontrar algumas variações quanto a definição de projeto, no entanto, todas seguem um mesmo sentido que é representado pelo desejo ou necessidade de se alcançar algum resultado em um determinado tempo, ou seja, consideram os projetos únicos e temporários. Projeto é uma palavra derivada do latim, proicio, que significa" lançar a diante" Maximiano (2009). Para ele um projeto é uma sequência de atividades temporárias com começo, meio e fim programados e que tem como o objetivo fornecer um produto. Um projeto é formado por um esforço não permanente, ou seja, temporário, para a criação de um produto ou serviço. Como não é permanente, pode-se evidenciar que todos os projetos deveriam conter um início, um desenvolvimento e um fim definido. $\mathrm{O}$ mesmo só chega ao seu fim quando seus objetivos são alcançados, quando não for mais necessário ou quando ficar bem claro que seus objetivos não poderão ser atingidos ou não é compensador ir em frente (VAlle et al, 2010).

Na ótica de Thiry-Cherques (2010), um projeto pode ser considerado como uma organização transitória, que compreende uma sequência de atividades dirigidas à geração de um produto ou serviço singular em um determinado tempo. A metodologia PRINCE 2, da OGC - Office of Government Commerce (2009), órgão do governo britânico, segue na mesma linha e define um projeto como uma organização temporária criada com o propósito de entregar um ou mais produtos de negócio, de acordo com um Business Case previamente definido. Segundo PRINCE 2, um Business Case é entendido como uma ideia que proporcionará um determinado valor agregado a organização, fazendo, dessa forma, com que a mesma mantenha o foco.

O PMI, Project Management Institute (2013), complementa as definições anteriores, afirmando que um projeto é caraterizado como um esforço temporário empreendido para criar um produto, serviço ou resultado exclusivo. A caracterização básica de um projeto é representada na Figura 1.

Figura 1 -Caracterização Projeto

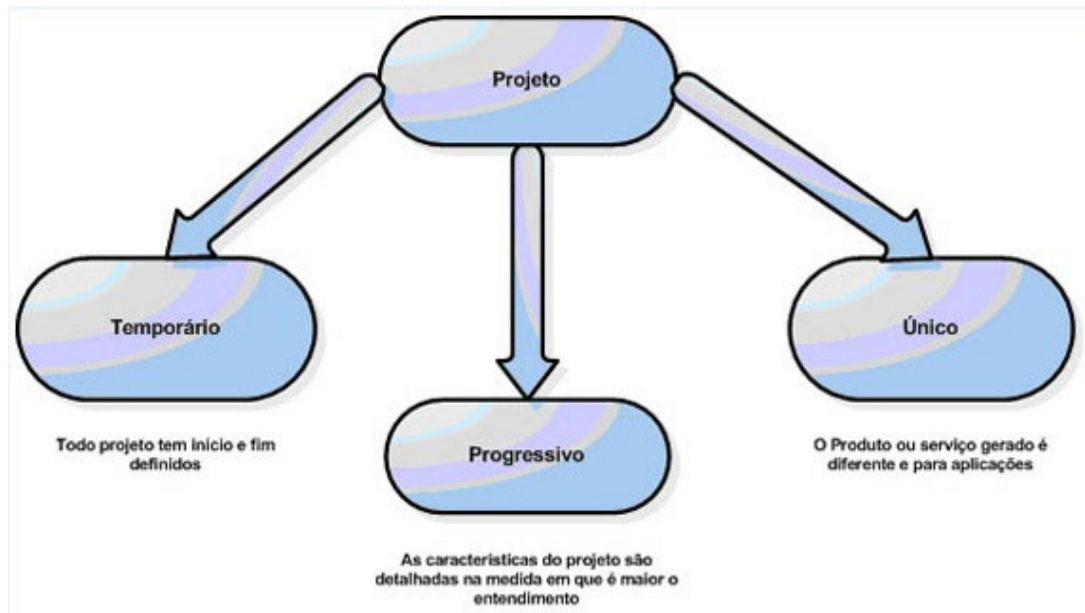

FONTE: PMI, 2000 
3

Entrega de produtos de cada fase de um projeto 4 Processo de subdivisão das entregas e do trabalho do projeto em componentes menores e mais facilmente gerenciáveis. É estruturada em árvore exaustiva hierárquica orientada às entregas, fases de ciclo de vida ou por subprojetos (deliverables) que precisam ser feitas para completar um projeto.

5

Project Management Body of Knowledge
Já a ISO 10006 (Diretrizes para qualidade de gerenciamento de projetos) apresenta outra definição de projeto, confirmando e complementando as anteriores,: um projeto é um processo único, consistindo de um grupo de atividades coordenadas e controladas com datas para início e término, empreendido para alcance de um objetivo conforme requisitos específicos. Um projeto é considerado progressivo porque, à medida que vai sendo compreendido, vai também, sendo elaborado. A forma progressiva de elaboração de um projeto traz um detalhamento das suas características e isso o distingue como como único (DINSMORE E CAVALIERI, 2003).

No que se refere ao fator temporalidade, embora os projetos sejam temporários, nem sempre os produtos ou serviços, que são os seus resultados, também o são. É um erro comum supor que, devido ao fato de ser temporário, um projeto será sempre de curta duração (VALle et al., 2010). Existem projetos que duram vários anos, mas, mesmo nesses casos, sua duração tem um fim bem definido. Como consequência do caráter temporário do projeto, suas atividades se desenvolvem dentro de um espaço finito de tempo, ao qual foi dado o nome de ciclo de vida. Por sua vez, o ciclo de vida pode ser subdividido em fases, as quais devem ser marcadas pela obtenção de um ou mais deliverables ${ }^{3}$, ou seja, produtos de fase, (Рмвок, 1996), onde cada fase de um projeto tem suas próprias características e necessidades (KEELLING, 2008). A medida que elas vão sendo desenvolvidas existe um aumento cumulativo de recursos e tempo despendido ao mesmo tempo que o prazo e recursos disponíveis diminuem gradativamente.

\section{GERENCIAMENTO DE PROJETOS}

Os registros históricos indicam que a gerencia efetiva de projetos tem sua origem nos Estados Unidos. O seu precursor foi Henry Gantt que era especialista em técnicas de planejamento e controle e utilizou o gráfico de 'barra' como uma ferramenta de gerência de projetos associando-a as teorias de Frederick Winslow Taylor da administração científica. Seu trabalho foi o precursor de muitas ferramentas de gerências modernas de projetos, tais como a WBS (Work Breakdown Structure) ou EAP (Estrutura Analítica do Projeto) ${ }^{4}$ de recurso, as quais, pretendem avaliar o trabalho. Em conjunto com Taylor, Henry Gantt (18611919) estudou detalhadamente a ordem de operações no trabalho. Os estudos de Henry Gantt sobre gerenciamento de atividades foram elaborados na construção de um navio durante a II Guerra Mundial. Gantt construiu diagramas com barras de tarefas e marcos que esboçam a sequência e a duração de todas as tarefas em um processo.

Antes dos anos 50, os projetos foram controlados, basicamente, pelos gráficos de Gantt e por técnicas informais. Em 1969, o Project Management Institute (PMI) foi dando forma ao PMBOK ${ }^{5}$, que se tornou na década de 80 o principal guia de referência para o gerenciamento de projetos. A premissa do PMI é que as ferramentas e as técnicas da gerência de projeto são similares nas áreas como a indústria 
"stakeholder" Aqueles grupos sem o apoio dos quais o empreendimento cessaria de existir do software, indústria de construção e demais áreas da economia. O gerenciamento de projetos começou a se tornar mais conhecido e utilizado pelas empresas nas décadas de 70 e 80. O ano de 1981 é marcado pela criação do guia de projetos desenvolvido pelo PMI e que se passou a chamar de Project Management Body of Knowledge (PMBOK). Esse documento continha os padrões e as linhas mestras das práticas que são usadas intensamente pelos gerentes de projetos.

Para Cleland e Ireland (2007), a disciplina de Gerência de Projetos surgiu modestamente na década de 1950, na indústria de construção, e posteriormente na indústria bélica, com o impulso da Guerra Fria e da Corrida Espacial, onde pode-se citar o Projeto Manhattan, referente à produção da primeira bomba atômica e o submarino nuclear Polaris. Compartilhando da mesma visão, Garel (2013), destaca que durante a segunda metade do século XX a gestão de projetos se afastou das demais teorias para ser identificada, evidenciada e generalizada, tornando-se um modelo de gestão, sendo que um artigo publicado na Harvard Business Review por Paul Gaddis (1959) é considerado a mais antiga referência explícita ao gerenciamento de projetos.

Em contrapartida, o modo formal de gerenciamento de projetos teve uma representatividade significativa desde o seu surgimento nos setores aeroespacial, de defesa e construção civil. É possível dividir a evolução de gestão de projetos em três fases. As décadas de 1960 a 1985 como a fase tradicional. Nos anos seguintes de 1985 a 1993, o período de renascimento. A terceira década é considerada a moderna no período de 1994 a 2003 (KERZNER, 2006). A primeira fase foi marcada por uma gestão de projetos de grande porte onde os custos e cronogramas ficavam quase sempre em segundo plano. A fase considerada como renascimento, se destaca pelas indústrias que começaram a aplicar os conhecimentos em projetos de pequeno porte. Finalmente, a fase moderna que é marcada pela a recessão de meados de 90 nos Estados Unidos onde as empresas americanas buscavam novas formas de gerenciar suas organizações com respostas internas mais rápidas. A partir de então, “a gestão de projetos havia se espalhado por praticamente todas as áreas de negócios, deixando de ficar restrita às unidades orientadas a projetos" (KERZNER, 2006, p.218)

Em relação ao momento atual da disciplina, Garel (2013, p. 2) destaca que "o status de gestão de projetos como teoria continua a competir por reconhecimento contra a sua dimensão profissional. Essa tensão é comum em disciplinas baseadas na prática, especialmente, quando são novas". Além disso, destaca que gestão de projetos vem passando por um processo de institucionalização, cujos principais responsáveis são os institutos de gestão de projetos. Para ele, na atualidade, o instituto mais representativo na área de gestão de projetos é o PMI.

Para o PMI (2013), gestão de projetos é o processo através do qual se aplicam conhecimentos, capacidades, instrumentos e técnicas às atividades do projeto de forma a satisfazer às necessidades e expectativas dos diversos stakeholders ${ }^{6}$ envolvidos no mesmo. Na literatura existem 
várias abordagens quanto à definição do conceito de gerenciamento de projetos, mas não existe um consenso quanto a uma específica que seja compartilhada. Em sua grande maioria, as definições abordam a mesma linha de raciocínio com algumas variações de conceitos.

No mundo globalizado de hoje, é possível perceber que o gerenciamento de projetos vem se fortalecendo cada vez mais, pois, as organizações estão percebendo que precisam gerenciar projetos para auxiliar no atingimento de seus objetivos e proporcionar melhores resultados, especialmente aqueles relacionados com custo e qualidade. Para Badewi (2015), a utilização da gerencia de projetos, por parte das organizações, pode trazer um aumento de eficiência do esforço humano na organização. Na mesma perspectiva, Gordillo (2016), afirma que o sucesso dos projetos depende da gestão deles. Além disso, destaca também que é importante as organizações entenderem que o sucesso de um projeto está atrelado à eficiência da gestão dos mesmos em curto prazo e aos resultados desejados em longo prazo.

É neste contexto que se insere o Moderno Gerenciamento de Projetos, com distintas metodologias, cada qual com vantagens e desvantagens, as quais, auxiliam a gestão no processo de tomada de decisão, pois permitem que o gestor saiba qual o método ou processo de trabalho deverá ser utilizado para uma das atividades. Além disso, também possibilitam a visualização das informações em tempo real ao alcance de toda a equipe envolvida. Porém, é preciso conhecer os recursos tecnológicos de cada ferramenta e analisar as reais necessidades da implantação de acordo com o projeto.

Neste contexto, Paumgartten (2010), afirma que as organizações que optarem pelo uso de ferramentas de gestão de projetos podem estar certas de que estão investindo corretamente, pois estarão executando projetos com maior probabilidade de sucesso e alcance de resultado positivos. Além disso, estarão ainda maximizando a utilização de recursos, fornecendo ferramentas de colaboração para conectar equipes dispersas e mantendo visibilidade e controle sobre o projeto através de relatórios e mensuração de resultados. Complementando essa visão, Joslin \& Müller (2015), corroboram afirmando que a gestão de projetos deve ser composta por metodologias e ferramentas que apoiem os projetos para que pelos menos sejam mais previsíveis.

\section{DIFERENÇAS DA GESTÃO DE PROJETOS: PÚBLICO X PRIVADO}

As diferenças na gestão de projetos entre o setor público e privado tem sido objeto de estudo de diversos pesquisadores há algum tempo (RING, PERRY,1985; NUTT, BACKOFF, 1993; BOYNE, 2002; CRAWFORD, HELM, 2009; WIRICK, 2009, ZWICKER, FETTKE, LOOS, 2010; PISA, OLIVEIRA, 2013). Entretanto, quando da implementação de teorias, metodologias e ferramentas, essas distinções muitas vezes são desconsideradas. A respeito disso, Meyer (1979), alerta que é importante a consideração dessas diferenças entre organizações orientadas para o lucro e instituições públicas, pois a desconsideração pode levar a uma generalização 
da teoria organizacional. Santos, Gonçalves e Dias (2012), complementam destacando como fator importante a preocupação do setor público quanto a importação de mecanismos de gestão de projetos, que eram originalmente usados no setor privado, uma vez que estas têm suas atividades voltadas especificamente para o alcance de resultados financeiros, já o Estado tem suas atividades voltadas exclusivamente para atender aos interesses da sociedade.

O setor público é um ambiente conflituoso que envolve diversos atores com interesses diferentes e que apresentam pouca preocupação com o risco (wirick, 2009). Para Valle et al. (2010), o grande desafio do setor público é conseguir mecanismos adequados para viabilizar um diálogo eficaz entre os objetivos e as ferramentas de gestão de projetos utilizadas pelo setor para o atingimento dos seus propósitos. Diante da crescente pressão popular e insatisfação da sociedade com as instituições públicas, faz-se necessário que haja uma busca por um incremento na eficiência da gestão, tendo o cidadão como principal beneficiário. Outro fator que tem influência sobre o aumento do interesse e importância da gestão de projetos no setor público é a elevação das exigências de controle e avaliações dos gastos públicos que vem ocorrendo em diversos países (CRAWFORD \& HELM, 2009).

Além disso, fica evidente a necessidade da busca pela modernização do Estado para que assim o mesmo se torne menos burocrático e mais competitivo. Na perspectiva de Ntlokombini (2010), essas novas tendências criam uma oportunidade para a utilização das práticas de gerenciamento de projetos em instituições públicas brasileiras. A esfera pública tem buscado utilizar com mais intensidade tais práticas como uma ferramenta facilitadora para o atingimento de um índice maior no êxito na implementação das políticas públicas. Essas ferramentas não só auxiliam na melhora do processo de implementação, como também possibilitam mensurar a eficiência, a eficácia e efetividade de suas ações (CARNeIro, 2010). Diferente das empresas privadas a Administração Pública possui características próprias, o que faz com que seja necessário a adoção de práticas diferenciadas para a gestão de projetos. Para Crawford \& Helm (2009), uma das importantes especificidades do setor público é a necessidade de satisfazer múltiplos e imprevisíveis stakeholders.

Em complemento Wirick (2009), destaca que a gestão das partes interessadas de um projeto público é um dos fatores de diferenciação mais presentes na literatura. Os projetos nesse setor têm a necessidade de considerar outros projetos e programas do governo e por isso acabam tendo mais stakeholders, dentro o seu modelo de gestão, que as instituições privadas. $\mathrm{O}$ conhecimento das partes interessadas e quais os resultados esperados pelos mesmos podem ser considerados um fator decisivo para o atingimento desempenhos satisfatórios nas organizações. A análise da satisfação dos stakeholders deve ser bastante criteriosa, pois ela pode ser considerada como um ponto chave para o sucesso da gestão de projetos nas organizações públicas, privadas e sem fins lucrativos (BRYSON, 2004). 
No entanto, segundo Gomes (2013), esta teoria necessita ser aperfeiçoada para poder ser considerada como uma ferramenta que possibilite auxiliar os gestores públicos no processo de análise da complexidade das relações formadas entre as suas organizações e os atores que habitam o ambiente em que operam. Na perspectiva de Mainardes et al. (2010), as organizações do setor público apresentam, em geral, uma quantidade de partes interessadas superior as organizações empresariais tradicionais. Isso acontece porque a administração pública envolve uma diversidade de atividades e um elevado número de pessoas, grupos e organizações que tem interesse nas atividades realizadas. A grande diversidade dos stakeholders, no setor público, acaba por gerar um modelo de avaliação múltiplo e disperso.

Outro diferencial do governo em relação ao setor privado é o processo decisório onde é necessário um relacionamento mais amplo e aberto com os stakeholders do que no setor privado (RING \& PERRY, 1985). Para Gomes e Liddle (2010), no momento que as organizações conseguem identificar, analisar e categorizar os stakeholders, as mesmas passam a ter maior conhecimento sobre o ambiente ao qual ela está inserida. Dessa forma, as instituições devem levar em consideração as fontes de influência e interesse quando da elaboração das suas estratégias. Bui (2017) complementa afirmando que é necessário a identificação dos stakeholders de uma forma clara, bem como também as suas expectativas. Para ele isso é necessário para que seja possível a implementação de relações adequadas com as mesmas.

Outro fator de diferenciação na gestão de projetos é a transparência e accountability. Enquanto que na área pública é necessária e cada vez mais exigida pela sociedade, no setor privado não existe essa necessidade, pois a gestão destas organizações existem para anteder aos interesses de um indivíduo ou um grupo. Para Crawford \& Helm (2009), esse fator é de grande importância e também de diferenciação para o setor público, uma vez que existe uma grande necessidade de transparência e accountability na implementação de políticas públicas que são desenvolvidas através de projetos. É necessário que a gestão pública atue de maneira aberta na gestão de seus projetos, sem omissão de informações sobre seus atos e que seja baseada em princípios éticos e democráticos. Esta pode ser considerada como uma condição essencial para possibilitar que a sociedade consiga desenvolver a sua participação social e como consequência exerçam a sua cidadania.

A administração pública deve buscar disponibilizar o máximo de informações sobre os projetos, pois maior será a probabilidade do cidadão de ser mais atuante e eficaz em sua participação no processo decisório dos governos (MENDANHA, 2009). Nessa perspectiva, Junior et. al. (2014), afirmam que é necessário que as instituições públicas realizem a promoção da transparência e o estímulo ao controle social para que seja possível um maior acesso ao cidadão quanto as informações da administração pública e por meio disso exercer maior vigilância sobre os atos dos agentes públicos. 
Neste sentido, diferente da área privada, percebe-se uma crescente preocupação dos gestores públicos com o desenvolvimento de canais, meios e portais de transparência pública para possibilitar uma maior aproximação entre o cidadão e o Estado. Porém de acordo com Khagram, De Renzio e Fung (2013), as relações entre transparência fiscal, participação e prestação de contas são, de maneira geral, fracas, erráticas e incompletas. Isto claramente representa um desfio para as organizações públicas, a necessidade de realizar a promoção da transparência.

Em seus estudos Boyne (2002), ao realizar uma revisão dos argumentos teóricos existente entre as diferenças apresentadas pelas empresas privadas e órgãos públicos, observou que existe um certo ceticismo nas literaturas quanto a adoção de modelos do setor privado na gestão pública. Destaca ainda que a existência de diferenças entre as organizações públicas e privadas tem agido como barreiras a transferência de técnicas de gestão do setor privado para o público. As principais hipóteses de contrastes entre organizações públicas e privadas, citadas por Boyne, são apresentadas no quadro a seguir.

QUADRO 1 - Hipóteses de contrastes entre organizações públicas e privadas.

MEIO AMBIENTE

H1: Os gestores públicos trabalham em um ambiente mais complexo

H2: As organizações públicas estão mais abertas a influências ambientais

H3: O ambiente de organismos públicos é menos estável

H4: Os gestores públicos enfrentam pressões competitivas menos intensas OBJETIVOS

H5: Os objetivos das organizações públicas são distintos

H6: Os gestores públicos são obrigados a exercer um maior número de objetivos

H7: Os objetivos dos órgãos públicos são mais vagos

ESTRUTURAS

H8: As organizações públicas são mais burocráticas

H9: Mais burocracia está presente na tomada de decisões pelas organizações públicas

H10: Os gerentes de agências públicas têm menos autonomia em relação aos órgãos superiores

VALORES

H11: Os gestores do setor público são menos materialistas

H12: A motivação para servir o interesse público é maior no setor público

H13: Os gestores públicos têm comprometimento organizacional mais fraco

FONTE: Boyne (2002)

Em seu trabalho traz como conclusão que o fato da existência de diferenças significativa, em função de diferenças em ambientes organizacionais, objetivos, estruturas e valores de gestão faz com que haja uma dificuldade na exportação das técnicas de gestão com sucesso de um setor para outro. Essas variáveis representam um conjunto de contingências que exigem abordagens diferentes para a gestão de projetos em órgãos públicos e empresas privadas. 
No mesmo contexto, Zwicker, Fettke e Loos (2010) complementam com seu estudo onde abordam as especificidades da Gestão de Processos na administração pública afirmando que as ações administrativas são afetadas diretamente pelos os princípios burocráticos, sendo essa uma das principais diferenças entre a administração pública e a privada. Dessa forma, para melhor apresentar essas especificidades os autores elaboraram um quadro comparativo entre princípios e características do setor público com os do privado conforme Quadro 2.

QUADRO 2 - Características de organizações dos setores público e privado.

\begin{tabular}{|c|c|c|}
\hline CARACTERÍSTICAS & PRIVADA & PÚBLICA \\
\hline $\begin{array}{l}\text { LEGALIDADE } \\
\text { DAS AÇÕES }\end{array}$ & $\begin{array}{c}\text { Ações essencialmente } \\
\text { ilimitadas, porém, alinha- } \\
\text { das à visão e objetivos da } \\
\text { organização }\end{array}$ & $\begin{array}{l}\text { Ações essencialmente } \\
\text { limitadas a leis e regula- } \\
\text { mentos (princípio } \\
\text { da legalidade) }\end{array}$ \\
\hline CONTROLE & $\begin{array}{l}\text { Mercado organização } \\
\text { econômica }\end{array}$ & Legitimação política \\
\hline $\begin{array}{l}\text { POSIÇÃO DE } \\
\text { MERCADO }\end{array}$ & Ambiente competitivo & $\begin{array}{c}\text { Ambiente não competi- } \\
\text { tivo (características de } \\
\text { monopólio) }\end{array}$ \\
\hline $\begin{array}{c}\text { ESTRUTURA } \\
\text { ORGANIZACIONAL }\end{array}$ & $\begin{array}{l}\text { Não estabelecida uma } \\
\text { estrutura, individual } \\
\text { a cada organização }\end{array}$ & $\begin{array}{l}\text { Estrutura hierárquica } \\
\text { rígida, possuindo linhas } \\
\text { claras de autoridade }\end{array}$ \\
\hline $\begin{array}{l}\text { REQUISITOS DE } \\
\text { DOCUMENTAÇÃ̃O }\end{array}$ & $\begin{array}{l}\text { Sem exigência explícita } \\
\text { de documentação }\end{array}$ & $\begin{array}{l}\text { Todas as decisões e } \\
\text { ocorrências devem ser } \\
\text { documentadas para } \\
\text { efeito de controle }\end{array}$ \\
\hline SEGMENTO DE CLIENTE & Quase sempre heterogêneo & Heterogêneo \\
\hline GAMA DE PRODUTOS & Quase sempre heterogêneo & Heterogêneo \\
\hline
\end{tabular}

Outra diferença destacada por Nutt e Backoff (1993), entre as organizações públicas e privadas é o processo de formulação de estratégias. Essa diferença impacta no seu modelo de gestão, seja ele institucional ou de projetos, e consequentemente a sua capacidade de geração de resultados. $\mathrm{O}$ setor privado define as suas estratégias para com foco na escolha dos segmentos de mercado dentro de sua área de atuação e isso possibilita as empresas testarem a adequação de suas estratégias a partir do feedback da dos resultados financeiros de lucratividade. Nessas instituições o lucro é a principal objetivo das empresas e as metas, em sua maioria, utilizam medidas de lucratividade como forma de selecionar as ações. Num contraponto, tem-se as organizações públicas que não utilizam o mesmo conceito para definição de suas estratégias, tampouco possuem algo próximo ou equivalente com o conceito de lucratividade. Nessas instituições as metas apresentam uma tendência de serem mais vagas, ambíguas e normalmente buscam cobrir e ou resolver diversos problemas. Como resultado desse processo as organizações públicas acabam apresentando dificuldades na definição de suas metas que, por consequência, afetam no desenvolvimento e avaliação de opções estratégicas. Um desses dilemas abordado por Crawford \& Helm (2009), é a oposição entre as necessidades sociais e as limitações orçamentárias do governo. 
Já quanto ao impacto dos projetos públicos Levy e Pauzner (2013), afirmam que os mesmos não podem ser avaliados apenas pela questão de resultados e desempenho financeiro, pois também proporcionam benefícios sociais, fator esse que os difere do setor privado. Nessa mesma linha, Ika (2015), afirma que além de critérios como a relevância do projeto para as prioridades de seu público alvo, que são os benefícios sociais ao cidadão, a efetividade do atendimento dos objetivos e a eficiência da adequação do uso de recursos, também devem ser observados como critérios de impacto dos projetos.

Na visão de Pisa e Oliveira (2013), na gestão de projetos é necessário levar em consideração mais algumas diferenças fundamentais entre organizações públicas e privadas: (I) o aspecto social dos projetos governamentais; (2) a obrigatoriedade da previsão dos recursos para execução do projeto em lei, mais especificamente na Lei Orçamentária Anual (LOA); (3) a obediência à Lei 8.666/93,que regula a contratação através de diversas modalidades, contemplando, de modo geral, o menor preço; (4) o excesso de normatizações, que provocam demoras na execução dos projetos; (5) a existências de diferentes órgãos de controle nas diversas esferas de governo; (6) a exigência de prestação de contas à sociedade em virtude dos princípios da transparência e accountability na governança pública.

Outro quesito de diferenciação entre os setores destacado como relevante é a política, que se caracteriza pela separação de poderes entre os níveis federal, estadual e municipal (RING \& PERRY, 1985). Não menos importante a governança é outra especificidade do setor público que o diferencia do privado. A gestão dos recursos no setor público é outra que requer a busca constante por novas ferramentas de gestão em função da demanda crescente por eficiência (NUTT \& BACKOFF, 1993).

No que se refere à questão dos aspectos financeiros de um projeto encontramos diferenças do setor público para o privado, especificidades essas que normalmente tornam o gerenciamento do projeto na gestão pública mais complexo. Na administração pública são muitos os projetos que necessitam de financiamentos feitos por organismos internacionais e multilaterais. Logo, projetos com financiamento desse tipo apresentam características diferentes daqueles encontrados no setor privado, pois no mesmo, a instituição se limita somente a conceder o crédito e cobrar o seu recebimento. Por outro lado, uma vez que essas organizações são as financiadoras de projetos públicos tem total interesse no processo de elaboração e execução podendo exercer influência direta sobre a maneira como os projetos são desenhados, monitorados e coordenados. Neste sentido, corroborando com estes argumentos, Ika (2015), traz indícios sobre a influência dessas organizações internacionais financiadoras de projetos públicos. Para tanto, realizou uma análise em mais de 178 projetos públicos financiados pelo Banco Mundial onde identificou que esse tipo de relação tem influência direta no sucesso da gestão do projeto.

Em função do contexto apresentado, com base nas considerações dos autores citados; e com o objetivo de demonstrar algumas das prin- 
cipais diferenças entre gestão de projetos públicos, desenvolveu-se o Quadro 3 que apresenta uma síntese das especificidades da gestão de projetos no setor público, em diferentes dimensões.

QUADRO 3 - Especificidades da gestão de projetos do setor público

\begin{tabular}{|c|c|c|}
\hline AUTOR/ANO & DIMENSÃO & DESCRIÇÃO \\
\hline $\begin{array}{l}\text { Santos, Gonçalves e Dias } \\
\text { (2012), Valle et al. (2010), } \\
\text { Carneiro (2010), Boyne } \\
\text { (2002), Crawford \& Helm, } \\
\text { (2009), Ntlokombini (2010) }\end{array}$ & $\begin{array}{l}\text { Ferramentas } \\
\text { de Gestão de } \\
\text { Projetos }\end{array}$ & $\begin{array}{l}\text { Preocupação do setor público quanto } \\
\text { a importação de mecanismos de gestão } \\
\text { de projetos, que eram originalmente } \\
\text { usados no setor privado e utilização dos } \\
\text { mesmos como ferramenta de auxílio } \\
\text { para mensurar a eficiência, a eficácia e } \\
\text { efetividade. }\end{array}$ \\
\hline $\begin{array}{l}\text { Crawford \& Helm (2009), } \\
\text { Mainardes et al. (2010), } \\
\text { Gomes e Liddle (2010), } \\
\text { Mainardes, Alves e } \\
\text { Raposo (2010), Bui (2017), } \\
\text { Jongbloed, Enders e Salerno } \\
\text { (2008), Ring \& Perry, (1985). } \\
\text { Gomes (2013), Bryson, } \\
\text { (2004), Wirick (2009) }\end{array}$ & Stakeholders & $\begin{array}{l}\text { Qualquer grupo ou indivíduo que pode } \\
\text { afetar o desenvolvimento de um projeto. } \\
\text { A satisfação das partes interessadas deve } \\
\text { ser bastante criteriosa. O setor público } \\
\text { apresenta um número mais elevado de } \\
\text { partes interessadas. Não basta identificar, } \\
\text { mas é necessário também conhecer as } \\
\text { necessidades. O principal stakeholders do } \\
\text { setor público é a sociedade. }\end{array}$ \\
\hline $\begin{array}{l}\text { Ring \& Perry (1985), } \\
\text { Boyne (2002) }\end{array}$ & $\begin{array}{l}\text { Processo } \\
\text { decisório }\end{array}$ & $\begin{array}{l}\text { É necessário um relacionamento mais } \\
\text { amplo e aberto com os stakeholders } \\
\text { do que no setor privado. }\end{array}$ \\
\hline $\begin{array}{l}\text { Crawford \& Helm (2009), } \\
\text { Mendanha (2009), Junior } \\
\text { et. al. (2014), Khagram, De } \\
\text { Renzio e Fung (2013), Pisa } \\
\text { e Oliveira (2013) }\end{array}$ & $\begin{array}{l}\text { Transparência e } \\
\text { accountability }\end{array}$ & $\begin{array}{l}\text { São fatores de grande importância e } \\
\text { diferenciação para o setor público, uma } \\
\text { vez que existe uma grande necessidade } \\
\text { de transparência e accountability na } \\
\text { implementação de políticas públicas que } \\
\text { são executadas por meio de projetos. } \\
\text { Busca pelo máximo de disponibilização } \\
\text { e informações de todos os projetos. }\end{array}$ \\
\hline $\begin{array}{l}\text { Zwicker, Fettke e Loos } \\
\text { (2010), Pisa e Oliveira } \\
\text { (2013), Boyne (2002) }\end{array}$ & $\begin{array}{l}\text { Gestão de } \\
\text { Processos }\end{array}$ & $\begin{array}{l}\text { São afetadas diretamente pelos os } \\
\text { princí-pios burocráticos, sendo essa } \\
\text { uma das principais diferenças entre } \\
\text { a administração pública e a privada. } \\
\text { Apresenta diversos órgãos de controle. }\end{array}$ \\
\hline Nutt e Backoff (1993) & $\begin{array}{l}\text { Formulação de } \\
\text { Estratégias }\end{array}$ & $\begin{array}{l}\text { Impacta no seu modelo de gestão de } \\
\text { projetos e consequentemente a sua } \\
\text { capacidade de geração de resultados. }\end{array}$ \\
\hline $\begin{array}{l}\text { Nutt \& Backoff (1993), Pisa } \\
\text { e Oliveira (2013) }\end{array}$ & $\begin{array}{l}\text { Gestão de } \\
\text { Custos }\end{array}$ & $\begin{array}{l}\text { A gestão dos recursos no setor público } \\
\text { é uma especificidade e requer a busca } \\
\text { constante por novas ferramentas de } \\
\text { gestão em função da demanda crescente } \\
\text { por eficiência. }\end{array}$ \\
\hline Ika (2015) & Financiamento & $\begin{array}{l}\text { As instituições financiadoras de projetos } \\
\text { no setor público, principalmente } \\
\text { internacionais podem exercer influência } \\
\text { sobre aspectos da gestão do projeto. }\end{array}$ \\
\hline $\begin{array}{c}\text { Ring \& Perry (1985), Pisa e } \\
\text { Oliveira (2013) }\end{array}$ & Política & $\begin{array}{l}\text { Separação de poderes eWntre os } \\
\text { níveis federal, estadual e municipal. } \\
\text { Interferência política no projeto. }\end{array}$ \\
\hline Wirick (2009) & Comunicação & $\begin{array}{l}\text { A administração pública apresenta uma } \\
\text { diversidade maior de canais e estilos } \\
\text { de comunicação em virtude da grande } \\
\text { variedade de stakeholders. }\end{array}$ \\
\hline $\begin{array}{l}\text { Levy \& Pazuner (2013), } \\
\text { Ika (2015) }\end{array}$ & $\begin{array}{l}\text { Impacto dos } \\
\text { projetos }\end{array}$ & $\begin{array}{l}\text { Necessitam levar em consideração as } \\
\text { variáveis sociais além das financeiras. }\end{array}$ \\
\hline
\end{tabular}

FONTE: Desenvolvido pelos autores (2018) 
Observa-se que as especificidades do setor público em relação à iniciativa privada, na gestão de projetos, são amplas e em diferentes aspectos. Foram identificadas onze dimensões de diferenciação, com destaque para um maior número de estudos referente a ferramenta de gestão de projetos, a identificação dos Stakeholders e questões ligadas a Transparência e accountability.

\section{CONSIDERAÇÕES FINAIS}

A partir de uma ampla revisão de literatura esse estudo buscou levantar algumas das principais especificidades da gestão de projetos na administração pública. Os resultados indicaram que existe um número bastante expressivo e relevante de diferenças da gestão de projetos públicos para o setor privado. É destacado pela maioria dos autores que a gestão de projetos é mais complexa no setor público, justamente porque essas especificidades em sua maioria tendem a burocratizar mais o processo de execução.

Como resultado da pesquisa, é possível concluir que as especificidades do setor público influenciam na gestão adequada de seus projetos. As principais diferenças na gestão de projetos públicos e privados envolveram as questões do aspecto social, onde os projetos públicos precisam ter uma preocupação quanto aos benefícios sociais e não somente questões financeiras como no setor privado. Uma preocupação que teve destaque foi a importação de mecanismos de gestão de projetos, que eram originalmente usados no setor privado, uma vez que são necessárias adaptações e ajustes da metodologia originalmente desenvolvida para o setor privado. A existência de diferentes órgãos de controle, diferente do setor privado. A necessidade da prestação de contas para a sociedade em virtude do princípio da transparência e accountability, o que não é necessário na área privada. O excesso de normatizações no setor público, que provocam muitas vezes demora na execução dos projetos, e a maior diversidade de stakeholders, onde o setor público apresenta um número mais elevado de partes interessadas.

No entanto, mesmo com esse processo mais engessado e com todas essas especificidades ainda é perceptível a existência de muitos atos falhos nos projetos públicos. Segundo levantamento feito pela Revista Exame (2016), através do "anuário Exame de Infraestrutura 2015 - 2016, das 10 maiores obras de infraestrutura que estavam em execução no país, verificou-se um aumento médio de $70 \%$ no orçamento em relação à previsão inicial.

Dessa forma, fica evidente que para um melhor gerenciamento da gestão de projetos no setor público é necessário que as iniciativas de implementação sejam conduzidas de forma concisa e efetiva e, levando em consideração as necessidades de adaptação e ajustes da metodologia originalmente mais desenvolvida para o setor privado, visando atender às especificidades do setor público.

Algumas evidências indicam que, atualmente existe ainda pouca maturidade no setor público quanto a utilização efetiva de ferramentas 
e técnicas de gerenciamento de projetos adequadas. Portanto, visualiza-se uma maior necessidade de preparação dos gestores públicos, para que a implementação da gestão de projetos se torne uma ferramenta mais eficiente na melhoria da gestão pública. Fato esse que já ocorre na área privada uma vez que existe uma maior maturidade na gestão de projetos nesse setor. Para Prado (2012), ter o domínio de metodologias de gestão de projetos tornou-se um dos aspectos de sobrevivência da empresa moderna. Para ele o gerenciamento de projetos apresenta uma relação direta com a eficiência no atingimento das metas da organização.

Assim, entende-se que a utilização mais efetiva da gestão de projetos no setor público, independentemente das dificuldades de implementação, é uma alternativa de fundamental importância para a administração pública como uma ferramenta capaz de auxiliar o processo de transformação do planejado em resultados, otimizando a alocação de recursos, diminuindo as surpresas e trazendo, por consequência, maiores ganhos em eficiência.

\section{REFERÊNCIAS}

ARCHIBALD, Russel D. \& PRADO, Darci. Pesquisa sobre maturidade em gerenciamento de projetos: Governo a Administração Direta e Indireta, 2015. Disponível em <http://www.maturityresearch.com/novosite/2014/ download/2/ Governo/ Relatorio Maturidade2014/Governo/ Parte/A/Indicadores.pdf $>$. Acessado em fev. de 2018.

AZMAN, M. A.; ABDUL-SAMAD, Z.; ISMAIL, S. The accuracy of preliminary cost estimates in Public Works Department (PWD) of Peninsular Malaysia. International Journal of Project Management, v. 31, n. 7, p. 994-1005, 2013.

BADEWI, A. The impact os projects management $(\mathrm{PM})$ an benefits management (BM) practices on project sucess: Towards developing a project benefits governance framework. International Journal of projet Management, 34(4), 761-778, 2015.

BESTEIRO, Elen Nara Carpim; NOVASKI, Olívio; PINTO, Jefferson de Souza; ANHOLON, Rosley. Fatores críticos de sucesso para o Gerenciamento de projetos: estudo Exploratório. Anais X congresso nacional de excelência em gestão, 2014.

BUI, Vinh Q. Stakeholder Identification in Vietnamese Private Higher Education Institutions. International Journal of Learning and Teaching Vol. 3, No. 1, March 2017. 
BRYSON, John M. Strategic planning for public and nonprofit organizations: a guide to strengthening and sustaining organizational achievement. $3 a$ ed. San Francisco: Jossey - Bass, 2004.

BOYNE, George A. Public and private management: what's the difference? Journal of Management Studies, v. 39, n.1, p. 97-122, Jan, 2002.

CLEMENTE, D. H.; MARX, R.; CARVALHO, M. M. Gestão de projetos no setor público: uma análise bibliométrica (1988-2014),. Gestão da Produção, Operações e Sistemas, Bauru, Ano 12, nº 2, abr-jun/2017, p. 1-20.

CLELAND, D. I.; IRELAND, L. R. Gerenciamento de Projetos, Revisão Técnica Rabechini Junior, R. 2. ed. Rio de Janeiro: LTC, 2007.

CARNEIRO, M. F. S. Gestão Pública: o papel do planejamento estratégico, gerenciamento de portfólio, programas e projetos e dos escritórios de projetos na modernização da gestão pública. Rio de Janeiro, RJ: Brasport, 2010.

CARVALHO, Kahan Elizabeth Monteiro; PISCOPO, Marcos Roberto. Fatores de Sucesso da Implantação de um PMO: Um Caso na Administração Pública. Revista Gestão \& Tecnologia, Pedro Leopoldo, v. 14, n. 3, p. 56-78, set./dez. 2014

CRAWFORD, Lynn H; HELM, Jane. Government and governance: The value of project management in the public sector. Project Management Journal. Volume 40, Issue 1, pages 73-87, March 2009.

DINSMORE, C. e CAVALIERI, A. Como se Tornar um Profissional em Gerenciamento de Projetos: Livro-Base de "Preparação para Certificação PMP - Project Management Professional". Rio de Janeiro, QualityMark, 2003.

GAREL, Gilles. A history of project management models: From pre-models to the standard models. International Journal of Project Management, v. 31, p. 663 - 669, 2013.

GOMES, Ricardo Corrêa "Em busca de uma teoria geral dos stakeholders para organizações públicas", em Joaquim F. Araújo, Hugo Consciência Silvestre (orgs.), Coletânea em Administração Pública. Lisboa, Escolar Editora, 2013.

GOMES, R. C.; LIDDLE, J.; GOMES, L. D. O. M.. A fivesided model of stakeholder influence: a cross-national analysis of decision making in local government. Public Management Review, v. 12, n 5, p. 701-724, 2010. 
GORDILLO, Angela Maria Benavides. Contribuição percebida das técnicas de gestão de projetos para os projetos de melhoria de processos. Dissertação (Mestrado). São Paulo, 2016. 144p. Universidade de São Paulo, 2016.

Institute, P.M. "PMSurvey.org", 2014

Edition - World Report, 2014.

IKA, A Lavgnon. Opening the black box of project management: Does World Bank project supervision influence project impact? International Journal of Project Management. Volume 33, Issue 5, July 2015, Pages 1111-1123.

JOSLIN, R.,\& MÜLLER, R. Relationships between a projetc management methodology an project sucessa in different project governance contexts. International Journal of project Management, 33(6), 1377-1392, 2015.

JONGBLOED, B.; ENDERS, J.; SALERNO, C. Higher education and its communities: interconnections, interdependencies and a research agenda. Higher education, v. 56, n. 3, p. 303-324, 2008.

JÚNIOR, T. M. O.; JORDÃO, C. S.; JUNIOR, J. L. P. C. Transparência, monitoramento e avaliação de programas no Brasil: em busca de opacidades que podem restringir o exercício do controle social. Revista do Serviço Público, Brasília 65 (1): 25-47 jan/mar 2014.

KEELING, R. Gestão de Projetos: uma abordagem global. São Paulo: Saraiva, 2008.

KHAGRAM, Sanjeev; DE RENZIO, Paolo; FUNG, Archon. Overview and Synthesis: The Political Economy of Fiscal Transparency, Participation, and Accountability around the World. In Open Budgets: The Political Economy of Transparency, Participation, and Accountability, edited by Khagram Sanjeev, Fung Archon, and De Renzio Paolo, 1-50. Brookings Institution Press, 2013.

KERZNER, Harold. Gestão de Projetos: As Melhores Práticas. 2. ed. Porto Alegre: Bookman, 2006.

KWAK, Y. H.; ANBARI, F. T. History, Practices and Future of Earned Value Management in Government: Perspectives From NASA. Project Management Journal, v. 43, n. 1, p. 77-90, 2012.

LEVY, Nadav; PAUZNER, Ady. Government's creditarating concerns and the evaluation of public projects. Journal of Public Economics. Volume 115, July 2014, Pages 117-130. 
MAINARDES, Emerson Wagner; ALVES, Helena; RAPOSO, Mário. As instituições de ensino superior no século XXI: Desafios para a gestão e relacionamento com os stakeholders. Reflexões sobre administração universitária e ensino superior. Blumenau: Edifurb, 2010.

MAXIMIANO, Antônio Cesar A. Introdução à Administração. 7.ed. São Paulo: Atlas, 2009.

MENDANHA, G. M. O direito de acesso à informação como fundamento da transparência. Revista da CGU, Brasília, v. IV, n. 6, p. 59-70, set. 2009.

MELO, Tâmara Patrícia Filgueira. Fatores críticos de sucesso para sistemas de informação de apoio ao gerenciamento de projetos. Anais XII Congresso Nacional de Excelência em Gestão \& III INOVARSE, 2016.

MEYER, J. W. The impact of the centralization of educational funding and control on state and local organizational governance. Stanford, CA: Institute for Research on Educational Finance and Governance, Stanford University, Program Report n. 79-B20, 1979.

NASCIMENTO, Thiago Cavalcante; DE SOUSA NETO, Manoel Veras; MILITO, Claudia Maria; MEDEIROS, Paulo César. Fatores que Contribuem para a Maturidade em Gerenciamento de Projetos: O Caso de Um Governo Estadual. In: Encontro da Associação Nacional de Pós-Graduação e Pesquisa em Administração - EnANPAD, 35, Rio de Janeiro, 2011. Anais Eletrônicos. Rio de Janeiro: ANPAD, 2011.

NTLOKOMBINI, Nyameko Nomhonxo Pearl. Project management as a catalyst for improved quality within organisations. 2010. 123 f. Dissertação (Mestrado) - Cape Peninsula University of Technology, Bellville, 2010.

NUTT, P. C.; BACKOFF, R. W. Strategy for public and thirdsector organizations. Journal of Public Administration Research and Theory, 3(2), 209-231, 1993.

OFFICE OF GOVERNMENT COMMERCE. Managing successful projects with PRINCE2. The Stationery Office, 2009.

PAUMGARTTEN, B. Ferramentas para gestão de projetos. Revista Engenharia de Software Magazine, Volume 45, 2010.

PISA, Beatriz Jackiu; OLIVEIRA, Antonio Gonçalves. Gestão de projetos na administração pública: um instrumento para o planejamento e desenvolvimento. $\mathbf{1}^{\mathbf{0}}$ seminário nacional de planejamento e desenvolvimento, Curitiba, PR, 2013. 
PRADO, D. O PMO e a Maturidade em Gerência de Projetos. In: BARCAUI, A. (Org.). PMO: Escritórios de Projetos, Programas e Portfólio na prática. São Paulo: Editora Brasport, 2012, p. 205-230.

PROJECT MANAGEMENT INSTITUTE - PMI.

A Guide to the Project Management Body of Knowledge (PMBoK). 5. ed. PMI Standard, 2013.

RING, Peter Smith and JAMES Perry, L. Strategic Management in Public and Private Organizations: Implications of Distinctive Contexts and Constraints. The Academy of Management Review, Vol. 10, No. 2,Apr., 1985, pp. 276/286.

SANTOS, Pedro Ferraz de Andrade Augusto dos Santos; GONÇALVES, Carlos Alberto; DIAS, Ana Valéria Carneiro. Implementação da Gestão de Portfólio de Projetos no Setor Público: Um estudo de caso no Governo de Minas Gerais. In: Encontro da Associação Nacional de Pós-Graduação e Pesquisa em Administração - EnANPAD, 36, Rio de Janeiro, 2012. Anais Eletrônicos. Rio de Janeiro: ANPAD, 2012.

SEGALA, M. Anuário Exame de Infraestrutura 2015-2016. Revista Exame, ed. 1099, ano 49, n.19, p. 106-117, out, São Paulo, SP, 2015.

SINGH, Rajendra; KEIL, Mark; KASI, Vijay. Identifying and overcoming the challenges of implementing a project management office. European Journal of Information Systems, Volume 18, Number 5, 1 October 2009, pp. 409-427(19)

SILVA, Polyana Tenório de Freitas; LIMA, Márcio Ferreira; NOGUEIRA, Thiago Maia Macêdo; SANTA RITA, Luciana Peixoto; SOUZA, Waldemar Antonio da Rocha. Fatores de sucesso de um projeto no setor público: um estudo sobre o guia de compras sustentáveis da UFAL. Revista UNIABEU, V.10, Número 25, maio-agosto de 2017.

THIRY-CHERQUES, H. R.. Modelagem de Projetos. São Paulo: Atlas, 2010.

VALLE, A. B. et al. Fundamentos de Gerenciamento de Projetos. 2.ed. Rio de Janeiro: Editora FGV, 2010.

VEZZONI, Guilherme; JÚNIOR, Antônio Carlos Pacagnella; JUNIOR, Ailton Luiz Banzi; SILVA, Sérgio Luis. Identificação e análise de fatores críticos de sucesso em projetos. Revista de Gestão e Projetos GeP, São Paulo, v. 4, n. 1, p 116-137, jan./abr. 2013. 
WINCH, G.M.; SANDERSON, J. Call for Papers Public policy and projects. International Journal of Project Management 33. 249-250, 2015

WIRICK, David. Publica Sector Project Management: Meeting the challenges and achieving results. John Wiley \& Sons, Inc. Hoboken, New Jersey, 2009.

ZWICKER, Jörg; FETTKE, Peter; LOOS, Peter. Business Process Maturity in Public Administrations. Berlin: Springer, 2010. 